\title{
The Importance of Aerosols in the Earth System: Science and Engineering Perspectives
}

\author{
Junji Cao ${ }^{1}$ (D)
}

Received: 1 February 2017/Revised: 11 April 2017/Accepted: 13 April 2017/Published online: 4 May 2017

(C) The Author(s) 2017. This article is an open access publication

\begin{abstract}
The significance of aerosol particles was first appreciated by physicists, chemists, and meteorologists, beginning in the 1880s. More recently, it has been shown that aerosols actively link the Earth's four spheres: the atmosphere, hydrosphere, biosphere, and lithosphere. Aerosol science and engineering have expanded to encompass nano- to global-scale issues, and the growing knowledge in these fields has been applied to some of the emerging global environmental challenges, including public health, air pollution, regional haze, and global warming. Some progress in these areas is briefly reviewed below and future perspectives are presented.
\end{abstract}

Keywords Aerosols · Earth's spheres - Aerosol engineering

\section{Definitions and a Short History}

An aerosol is technically defined as a suspension of fine liquid and/or solid particles in a gas, but in common usage "aerosol" often refers to the particulate phase alone. John Aitken began his pioneering research on condensation in 1875 , and he published his findings concerning atmospheric aerosols in the 1880s (Aitken 1880, 1888). Both basic and applied aerosol studies began to increase in earnest in the mid-1900s, and aerosol research now has a rich history that has been influenced by renowned physicists, chemists, meteorologists, and so forth. Political and

\section{Junji Cao}

jjcao@ieecas.cn

1 Institute of Earth Environment, Chinese Academy of Sciences, Xi'an, China economic events and technological developments have also shaped our understanding of the atmospheric aerosol and the many ways in which they affect our lives (Spurny 2001).

Indeed, aerosols play critical roles in a variety of processes that impact on our lives either indirectly (e.g., climate) or directly (e.g., environment, health). Recently, aerosol research has become a hot topic because of the growing concerns over air pollution and climate change (e.g., IPCC 2013; Huang et al. 2014).

\section{Aerosols in the Earth System}

The earth environment produces aerosol particles in a multitude of forms, including mineral dust, black carbon, organic carbon and sea salt from natural sources, and particles rich in sulfate, nitrate and ammonia from anthropogenic ones. These aerosols provide linkages among the Earth's atmosphere, hydrosphere, biosphere, and lithosphere (Fig. 1) because they have significant effects on key components of the Earth's systems such as the atmospheric radiative balance, regional hydrologic cycles, and the biogeochemical cycles of key elements, including sulfur, nitrogen, iron, etc. The wet and dry deposition of aerosol species can affect some key ecosystems through soil acidification and by providing micronutrients, such as soluble iron, to marine phytoplankton. The physical, chemical, and biological systems that produce these aerosols may be susceptible to modifications through climate change, and so there are potentially important feedbacks between aerosol populations and climate.

Large quantities of naturally derived aerosols are produced through the wind-driven erosion of deserts and soils. Estimates of the global production of mineral aerosol range 
Fig. 1 Aerosols in the Earth system: the active linking of Earth's four spheres

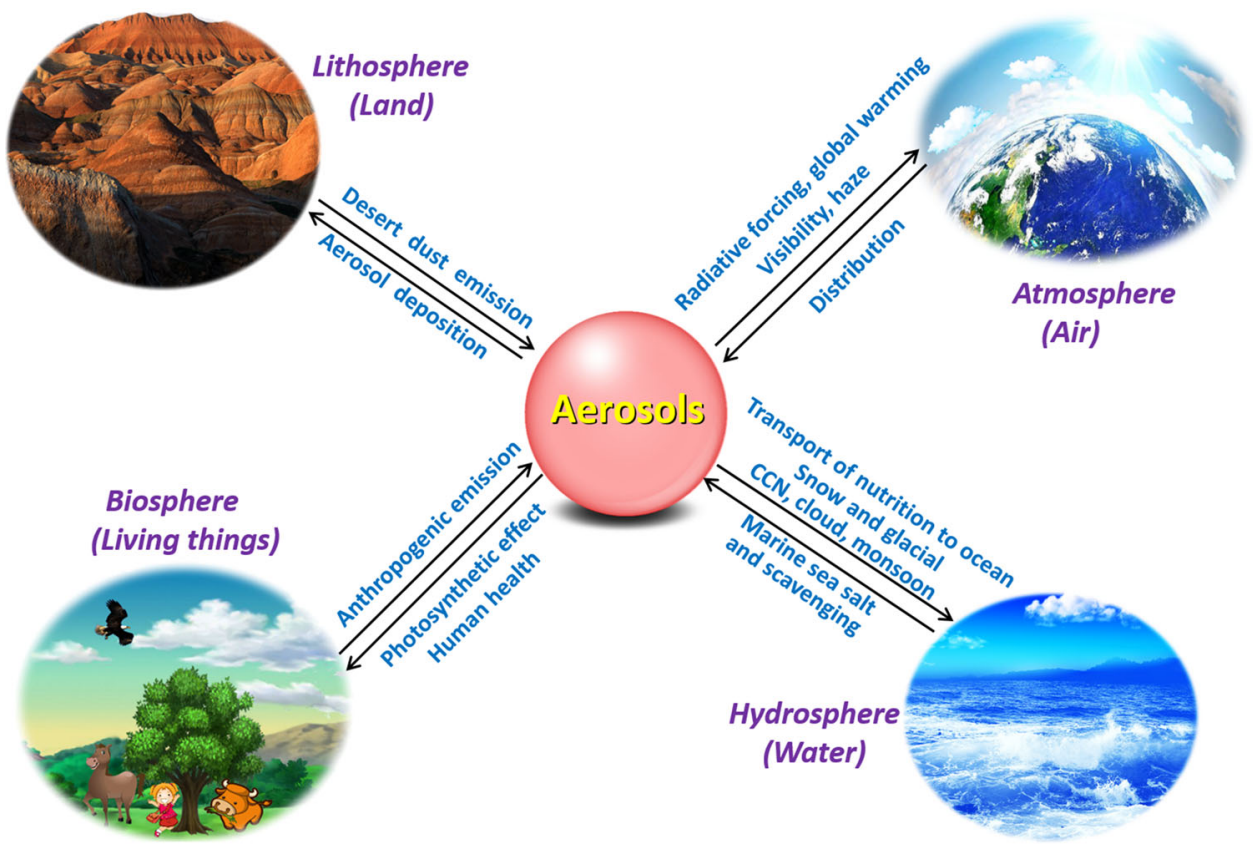

from 1000 to 5000 million tons/yr (Duce 1995), and there is very strong spatial variability in the dust sources. Human activities can disturb lands and increase soil particle mobilization and, therefore, there is an anthropogenic component to the dust production as well as a natural one. Changes in climate over geologic timescales also affect dust fluxes and loadings as has been shown in a series of classical studies of the Chinese loess plateau (An and Kukla 1991). Wind-driven erosion is a fairly continuous process; however, most aerosol production is the result of infrequent intense dust storms (Graedel 1993).

The ocean is an important source for aerosols in the form of atmospheric sea salt. It is estimated that the total emission of sea salt aerosols is $\sim 1300$ million tons/year (Schlesinger 1997). Sea salt and eolian dust are both relatively large in size and thus these particles tend to settle out of suspension rather quickly. Naturally derived sulfate aerosols form through the oxidation of dimethylsulfide produced by marine phytoplankton, and these biogenic particles may affect climate through their scattering of radiant energy.

Volcanoes episodically emit large quantities of ash and dust high into the atmosphere. Estimates of volcanically derived aerosols range from 4000 to 10,000 tons/year. Aerosols from large volcanic eruptions can perturb the global radiation budget through their effects on radiative fluxes, and they can also impact the carbon cycle. As an example of climate impacts, the Mount Pinatubo eruption in 1991 caused an estimated $0.6{ }^{\circ} \mathrm{C}$ decrease in the global mean temperature for 2 years following the event (Ruddiman et al. 2001).

Anthropogenic aerosols are mainly emitted from urban regions and industrial centers. Most of these particles are produced from fuel combustion, industrial emissions, transportation, and residential activities. The total production of primary aerosols is about 100-200 tons/year. In addition, agriculture activities and biomass burning can produce carbonaceous aerosols that are strong light absorbers.

Secondary aerosols form through the oxidation of precursor gases in the atmosphere, especially nitrogen oxides, sulfur dioxide, and some organic compounds. Sulfates, nitrates, ammonium, and secondary organic aerosols are the most common secondary aerosols, and they can originate from either anthropogenic or natural sources, but in most continental areas they are largely the result of industrial emissions.

The concentrations and distributions of aerosols vary geographically depending upon the proximity of continental, oceanic, and anthropogenic sources. In addition to the geographical variability in sources, there can be strong temporal effects as well due to episodic events as well as seasonal and longer term changes in sources. On a global basis, aerosol mass loadings are predominantly controlled by the natural sources that produce sea salt and dust. Mineral dust and anthropogenic aerosols typically dominate aerosol populations over the land while over the oceans, sea salt aerosols and some continentally derived aerosols predominate. The impact of anthropogenic aerosols is mainly restricted to the northern hemisphere (Graedel 1993), but aerosol pollutants have been transported over the entire globe. High loadings of aerosol sulfate and nitrate are found downwind of industrialized regions in Asia, North America, and Eastern Europe. Black carbon is generally most concentrated over eastern China 
and Eastern Europe, and large quantities of organic carbon aerosols also are found in these regions as well as over central South America and Africa where biomass burning is commonly used for agricultural purposes.

\section{Development of Aerosol Science and Engineering}

Aerosols can absorb or scatter light, and through these effects, the particles can directly affect the Earth's radiative balance (the "direct effect") and hence climate. Aerosols also can influence the formation of clouds and affect precipitation efficiency, thereby causing indirect radiative forcing (the "indirect effects") (IPCC 2013). It has been estimated that the total global mean direct anthropogenic aerosol radiative forcing at top of the atmosphere is $-0.22 \mathrm{~W} \mathrm{~m}^{-2}$, with a range from -0.63 to $+0.04 \mathrm{~W} \mathrm{~m}^{-2}$ (IPCC, 2013). This estimate does not include the anthropogenic contributions to nitrate and dust, which could add another $-0.2 \mathrm{~W} \mathrm{~m}^{-2}$. Estimates of the aerosol's effects are much smaller than those for the total greenhouse gas forcing $\left(+2.9 \mathrm{~W} \mathrm{~m}^{-2}\right)$, but simply comparing global average values does not take into account the large spatial and temporal variability in aerosol concentrations. This variability of aerosol distributions is one of the main reasons for the difficulties in estimating the magnitude of aerosol radiative forcing and for assessing the significance of these effects. Additional uncertainties in aerosol radiative forcings arise because of our incomplete understanding of the optical properties of the most important radiatively active species, especially black carbon, brown carbon, and dust.

Aerosol particles affect the hydrological cycle because they act as cloud condensation and ice nuclei, thereby influencing the formation and development of clouds. Aerosols also can affect cloud albedo and the concentrations of water droplets in the clouds; these in turn affect the brightness of clouds and, therefore, the scattering of both short- and long-wave radiation (Graedel 1993). The aerosols' effects on solar radiation and the temperature structure of the lower atmosphere may cause changes in evaporation and convection, and this is another way in which they can impact the hydrological cycle (Ramanathan et al. 2001). Recently, a new paradigm was proposed for aerosol-monsoon interactions, according to which natural aerosols, such as desert dust, black carbon, and biogenic aerosols, would be considered integral components of an aerosol-monsoon climate system. These intrinsic components would be subject to external forcings driven by global climate change, anthropogenic aerosol production, and changes in land use ( $\mathrm{Li}$ et al. 2016).

As the importance of atmospheric aerosol for the earth's systems has been recognized, aerosol science and engineering have become increasingly integrated, and the research has quickly expanded to cover nano-micro to hemisphere scales. The emerging global challenges for aerosol research include personal and public health, air pollution, regional haze, and global warming (Fig. 2). For example, Cao et al. (2012) found that fine aerosol ( $\left.\mathrm{PM}_{2.5}\right)$ constituents from the combustion of fossil fuel may have an appreciable influence on the health effects in Xi'an based on daily observation during 2004-2008. Tie et al. (2016) investigated the effect of regional haze pollution on the yields of rice and wheat in China and they found reduction of solar irradiance can depress optimal yields of about $45 \%$ of rice and $75 \%$ of wheat growth, leading to $1 \%$ reduction in total rice production and $4.5 \%$ reduction in total wheat production in China.

In addition to the research frontiers involving aerosols, health, the environment, and climate, some exciting prospects for aerosol engineering projects have emerged, and they are being explored as practical solutions to some of the environmental challenges facing contemporary society. Below is a brief sampling of the results from some recent studies.

\subsection{Nano-Microscale Aerosol Engineering}

New technologies for nanometer-sized aerosols, that is, particles with aerodynamic diameters of 100-1000 nm, are being developed for air purification, especially for industries (e.g., clean rooms for high-purity manufacturing) and for the removal of pollutants from ambient air. Recently, a novel fullerene-based nano-fiber filtration composite material was synthesized by means of melt-blown and electrostatic spinning technologies. The composite materials produced consisted of one-dimensional, continuous, organic-inorganic, nano-fiber spin-distorted structures, consistent with the bionic functions of natural fibers. These materials have been adopted for the removal of organic matter in indoor air, for water treatment, and other purposes; and it is expected that these methods can be scaled up for large engineering applications. Liu et al. (2015) developed a $\sim 90 \%$ transparent and high-airflow-adaptable filtration material screen with $\sim 95 \%$ efficiency for the removal of PM2.5 under extremely hazardous and heavypolluted conditions, and Pui et al. (2008) established a recirculating air filtration system capable of removing and reducing exposure to airborne nanoparticles.

\subsection{Local-Mesoscale Aerosol Engineering}

An innovative solar-assisted, large-scale cleaning system (SALSCS) is being developed by Prof. David Pui to remediate urban air problems on local- to mesoscales. The system consists of a large flat-plate solar collector, a 
Fig. 2 Impacts of aerosol from different scales in Earth

\section{Solar-Assisted Large-Scale Cleaning System (SALSCS) for Urban Air} collector, (2) chimney, (3) filter bank, and (4) fan/turbine (optional)
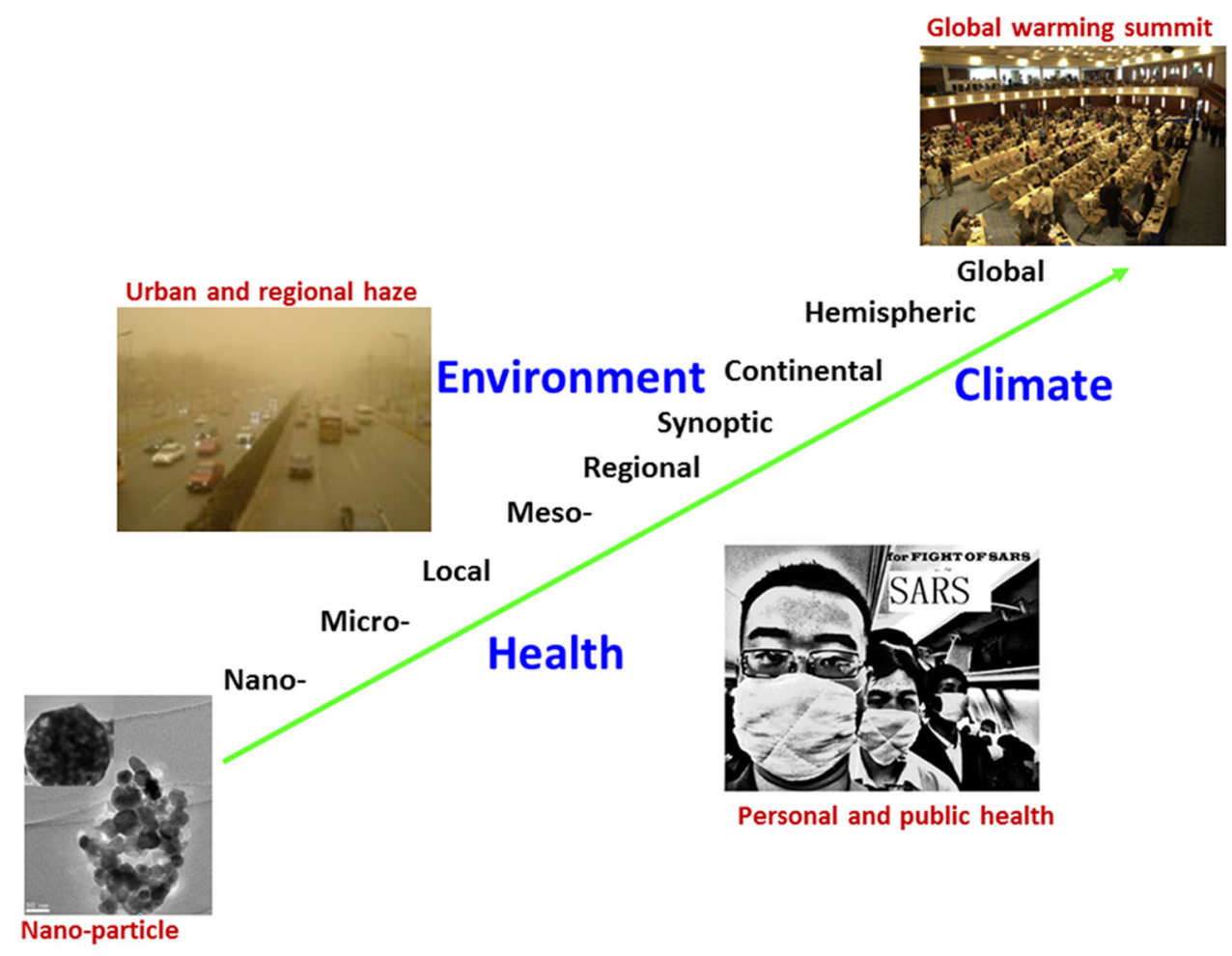

chimney, and a filter bank. In the basic configuration, the air flow is driven exclusively by buoyancy generated in the collector-chimney system, and $\mathrm{PM}_{2.5}$ and larger particles are separated from the air in the filter bank (Fig. 3) (Cao et al. 2015). Proof of concept has been obtained by means of a transient 3D numerical simulation of fluid and heat flow for a full-scale system, implemented in ANSYS Fluent and performed using high-performance computing techniques. The effects of the filter bank on the system performance, including heat transfer and fluid flow characteristics, have been evaluated by studying two system configurations, one with and one without a filter bank, 
respectively. The proposed SALSCS system is expected to be capable of processing atmospheric air at a flow rate of $2.64 \times 10^{5} \mathrm{~m}^{3} / \mathrm{s}$; this corresponds to a volume of $22.4 \mathrm{~km}^{3}$ of polluted air remediated in $24 \mathrm{~h}$. Currently, a demonstration unit has been developed and deployed in $\mathrm{Xi}$ 'an, China to test the SALSCS concept. If the tests prove to be successful, this approach could be used to treat the ambient environment in addition to the sources as another way of dealing with air pollution in China and other parts of the world.

\subsection{Regional-Synoptic-Scale Aerosol Engineering}

The idea for a great wall of solar panels to mitigate yellow dust storms in China has been proposed (Pui et al. 2014) as a regional-synoptic-scale engineering project. The proposal is to build windbreaks equipped with solar panels near the dust source areas: the solar panels would generate electricity on sunny days while the walls would provide windbreaks and remove airborne dusts during wind storms. Preliminary calculations indicate the walls would be capable of removing a large fraction of the airborne dusts and the amount of generated electricity could be significant. More detailed studies are needed to prove the feasibility of this approach.

\subsection{Continent-Hemisphere-Scale Aerosol Engineering}

Geo-engineering projects involving stratospheric sulfate aerosols have been proposed as a way to limit the effects and impacts of climate change due to the rising levels of radiatively active gases (Launder and Thompson 2008). The ability of stratospheric sulfate aerosols to cause a global dimming effect has made them a candidate for engineering projects designed to alleviate global warming (Crutzen 2006). The delivery of precursor sulfide gases, such as sulfuric acid, hydrogen sulfide, or sulfur dioxide, to the desired location could be accomplished through the use of artillery, aircraft, or balloons (Rasch et al., 2008). Some advantages of this possible remedy to global warming are (1) the effects would be rapid, (2) the implementation costs would be low, and (3) the changes would be reversible. According to some preliminary estimates, one kilogram of well-placed sulfur in the stratosphere could offset the warming caused by several hundred thousand kilograms of carbon dioxide.

\section{Future Perspectives}

Studies over the past hundred years have shown that aerosols play complex and important roles in earth systems, and yet fundamental research on their physical, chemical and biological properties is still needed to solve the important global challenges of air pollution, regional haze, global climate change, etc. At the same time, aerosol engineering innovations are being developed to keep pace with the scientific research and to tackle these emerging problems on a variety of spatial scales. Thus, both aerosol science and engineering will lead to a better understanding of aerosols in the context of Earth systems and how they can be involved in the sustainable development of our planet.

Acknowledgements This study was supported by the National Natural Science Foundation of China (41230641).

Open Access This article is distributed under the terms of the Creative Commons Attribution 4.0 International License (http://crea tivecommons.org/licenses/by/4.0/), which permits unrestricted use, distribution, and reproduction in any medium, provided you give appropriate credit to the original author(s) and the source, provide a link to the Creative Commons license, and indicate if changes were made.

\section{References}

Aitken J (1880) On dust, fogs, and clouds. Nature 14:384-385

Aitken $\mathrm{J}$ (1888) On the number of dust particles in the atmosphere. Nature 37:187-206

An Z, Kukla G (1991) Late quaternary dust flux on the Chinese Loess Plateau. Catena 18(2):125-132

Cao JJ, Xu HM, Xu Q, Chen BH, Kan HD (2012) Fine particulate matter constituents and cardiopulmonary mortality in a heavily polluted Chinese city. Environ Health Perspect 120(3):373-378

Cao QF, Pui YH, Lipiński W (2015) A concept of a novel solarassisted large-scale cleaning system (SALSCS) for urban air remediation. Aerosol Air Qual Res 15:1-10

Crutzen PJ (2006) Albedo enhancement by stratospheric sulfur injections: a contribution to resolve a policy dilemma? Clim Change 77(3-4):211-220

Duce R (1995) Sources, distributions, and fluxes of mineral aerosols and their relationship to Climate. Charlson RJ, Heinteznberg J (eds). John Wiley \& Sons Ltd

Graedel TE, Crutzen PJ (1993) Atmospheric change: an earth system perspective, W. H. Freeman Press

Huang RJ, Zhang YL, Bozzetti C et al (2014) High secondary aerosol contribution to particulate pollution during haze events in China. Nature 514:218-222

IPCC (2013) Climate Change 2013: The Physical Science Basis. Contribution of Working Group I to the Fifth Assessment Report of the Intergovernmental Panel on Climate Change [Stocker TF, Qin D, Plattner G-K, Tignor M, Allen SK, Boschung J, Nauels A, Xia Y, Bex V, Midgley PM (eds.)]. Cambridge University Press, Cambridge, United Kingdom and New York, NY, USA, p 1535

Launder B, Thompson JMT (2008) Global and Arctic climate engineering: numerical model studies. Phil Trans R Soc A 366(1882):4039-4056

Li ZQ, Lau KM, Ramanathan V, et al (2016) Aerosol and monsoon climate interactions over Asia. Rev Geophys 54. doi:10.1002/ 2015RG000500

Liu C, Hsu PC, Lee HW, et al. (2015) Transparent air filter for highefficiency $\mathrm{PM}_{2.5}$ capture. Nat Commun 6. doi: 10.1038/ ncomms7205, 2015 
Pui YH, Qi CL, Stanley N et al (2008) Recirculating air filtration significantly reduces exposure to airborne nanoparticles. Environ Health Perspect 116:863-866

Pui YH, Cao JJ, An ZS et al (2014) Great wall of solar panels to mitigate yellow dust storm. Particuology 13:146-150

Ramanathan V et al (2001) Aerosols, climate and the hydrological cycle. Science 294:2119-2124

Rasch PJ, Tilmes S, Turco RP et al (2008) An overview of geoengineering of climate using stratospheric sulphate aerosols. Philos Trans Ser A Math Phys Eng Sci 366(1882):4007-4037
Ruddiman WF (2001) Earth's climate, past and future. W. H. Freeman Press

Schlesinger WH (1997) Biogeochemistry: an analysis of global change, Academic Press

Spurny KR (2001) Historical aspects of aerosol measurements. Baron PA, Willeke K (eds) John Wiley and Sons Inc., pp 3-30

Tie XX, Huang RJ, Dai WT, Cao JJ, Long X, Su XL, Zhao SY, Wang QY, Li GH (2016) Effect of heavy haze and aerosol pollution on rice and wheat productions in China, Scientific Reports, 6 